\title{
Análise da eficiência hidrológica dos parques urbanos localizados na bacia do córrego Botafogo, Goiânia, GO
}

Analysis of the hydrological efficiency of urban parks located in the Botafogo river basin, Goiânia, GO

Análisis de la eficiencia hidrológica de los parques urbanos ubicados en la cuenca del arroyo Botafogo, Goiânia, GO

\section{Resumo}

A existência e preservação de parques urbanos ou áreas com remanescentes de vegetação em meio a ambientes densamente urbanizados se constitui em importante alternativa de manutenção das funções hidrológicas do solo próximas de suas características naturais, atenuando os desequilíbrios decorrentes do adensamento urbano nos processos físicos, em especial os hidrológicos. Neste sentido, com o presente trabalho objetivou-se avaliar a eficiência hidrológica de áreas com vegetação remanescente na bacia hidrográfica do córrego Botafogo em Goiânia. A metodologia compreendeu a avaliação das estimativas de velocidade de escoamento, precipitação efetiva, potencial de infiltração e coeficiente de escoamento superficial de áreas que passaram por adensamento urbano e de áreas que se mantiveram preservadas entre os anos de 1988, 1998, 2008 e 2018. Os resultados indicam aumento médio de 3,8 m/s nas velocidades de escoamento, aumento da precipitação efetiva, redução do potencial de infiltração, bem como aumento dos coeficientes de escoamento superficial, especialmente em áreas densamente urbanizadas. Para as áreas preservadas a tendência foi de manutenção dos valores das variáveis hidrológicas no período avaliado. Destaca-se que as áreas de vegetação remanescente tendem a sofrer os efeitos do escoamento superficial de áreas densamente urbanizadas localizadas à montante, com o escoamento concentrado provocando processos erosivos até mesmo em áreas vegetadas. Desta forma, destaca-se a importância da manutenção, bem como da instalação de áreas verdes em ambientes urbanos como forma de atenuar os desequilíbrios, especialmente aqueles relacionados às funções hidrológicas do solo.

Palavras-chave: Adensamento urbano; Remanescentes de vegetação; Potencial de infiltração.

\begin{abstract}
The existence and preservation of urban parks or areas with vegetation remnants in may densely urbanized environments is an important alternative to maintain the hydrological functions of the soil next to its natural characteristics, mitigating the imbalances arising from urban densification in physical processes, especially hydrological. In this sense, the present study aimed to evaluate the hydrological efficiency of areas with remaining vegetation in the watershed of the Botafogo stream in Goiânia. The methodology comprised the evaluation of estimates of runoff velocity, effective precipitation, infiltration potential and runoff coefficient of areas that underwent urban densification and areas that remained preserved between the years 1988, 1998, 2008 and 2018. The results indicate an average increase of $3.8 \mathrm{~m} / \mathrm{s}$ in runoff velocities, increased effective precipitation, reduced infiltration potential, as well as increased runoff coefficients, especially in densely urbanized areas. For the preserved areas the tendency was to maintain the values of hydrological variables in the evaluated period. It is noteworthy that the
\end{abstract}


remaining vegetation areas tend to suffer the effects of surface runoff from densely urbanized areas located upstream, with the concentrated runoff causing erosive processes even in vegetated areas. Thus, the importance of maintenance as well as the installation of green areas in urban environments is highlighted as a way to mitigate imbalances, especially those related to hydrological functions of the soil.

Keywords: Urban density; Vegetation remnants; Infiltration potential.

\section{Resumen}

La existencia y preservación de parques urbanos o áreas con remanentes de vegetación en mayo a entornos densamente urbanizados es una alternativa importante para mantener las funciones hidrológicas del suelo cercanas a sus características naturales, mitigando los desequilibrios derivados de la densificación urbana en los procesos físicos, especialmente los hidrológicos. En este sentido, el presente trabajo tuvo como objetivo evaluar la eficiencia hidrológica de las áreas con vegetación remanente en la cuenca del arroyo Botafogo en Goiânia. La metodología comprendió la evaluación de las estimaciones de la velocidad de escorrentía, la precipitación efectiva, el potencial de infiltración y el coeficiente de escorrentía de las áreas que sufrieron densificación urbana y las áreas que permanecieron preservadas entre los años 1988, 1998, 2008 y 2018. Los resultados indican un aumento medio de 3,8 $\mathrm{m} / \mathrm{s}$ en las velocidades de escorrentía, un aumento de la precipitación efectiva, una reducción del potencial de infiltración, así como un aumento de los coeficientes de escorrentía, especialmente en las zonas densamente urbanizadas. Para las zonas conservadas, la tendencia fue a mantener los valores de las variables hidrológicas en el periodo evaluado. Se destaca que las zonas de vegetación restantes tienden a sufrir los efectos de la escorrentía superficial procedente de las zonas densamente urbanizadas situadas aguas arriba, y la escorrentía concentrada provoca procesos erosivos incluso en las zonas con vegetación. De este modo, se destaca la importancia del mantenimiento así como de la instalación de zonas verdes en los entornos urbanos como forma de mitigar los desequilibrios, especialmente los relacionados con las funciones hidrológicas del suelo.

Palabras clave: Densidad urbana; Restos de vegetación; Potencial de infiltración.

\section{Introdução}

A urbanização pode ser entendida como conceito geográfico que representa a formação e crescimento das cidades. Quando há planejamento inadequado, consequentemente, ocorre o adensamento urbano acelerado, trazendo impactos ambientais significativos. Um dos fatores decorrentes do processo de urbanização descontrolada é o uso e ocupação do solo urbano sem o devido delineamento, originando recortes no terreno, que podem causar deslizamentos, além da compactação e impermeabilização do solo que afeta diretamente o escoamento superficial, podendo resultar em alagamentos e inundações.

Sob o ponto de vista dos impactos da urbanização nas bacias hidrográficas, é possível constatar, que as ocupações desordenadas em bacias, inseridas em cidades, trazem consequências à drenagem urbana, justamente por diminuir, ou até mesmo extinguir, as áreas naturais destinadas a infiltração e o armazenamento de água no lençol freático.

Para Tucci (2008), esses impactos ocorrem em decorrência de descontrole do espaço urbano, que produz efeito direto sobre a infraestrutura de água: abastecimento, esgotamento sanitário, águas pluviais (drenagem urbana e inundações ribeirinhas) e resíduos sólidos. Dentre os problemas decorrentes podem ser citados os eventos de elevados picos de vazão, os quais podem comprometer a circulação de pessoas e veículos, podendo resultar em elevadas perdas.

Na Região Metropolitana de Goiânia, não bastasse o adensamento populacional, acrescentam-se lotes cada vez menores nas regiões centrais ou nas margens das vias de circulação, impactando a dinâmica hidrológica (Kneib, 2016).

De acordo com Araújo et al. (2008), quando acontece o processo de urbanização, os espaços permeáveis, inclusive as áreas com presença de vegetação, são submetidas a diferentes tipos de usos, os quais tendem a impermeabilizar a superfície, causando aumento no escoamento superficial e deixando os cursos hídricos suscetíveis à alagamentos e inundações.

Santiago et al. (2020) ressaltam a importância de incorporar a natureza e as questões ambientais nas diretrizes urbanas, visto que a inserção de áreas verdes no contexto das grandes cidades pode contribuir para uma reurbanização, mesmo que em menor escala. Esse processo resulta em mudanças nas propriedades, tais como permeabilidade e porosidade, e no comportamento dos solos, em face da ocorrência de chuvas, com efeitos notórios, principalmente na dinâmica hidrológica das bacias hidrográficas (Hammond et al., 2013). 
Martins (2012) explica que a gestão dos sistemas de drenagem urbana envolve medidas estruturais e não estruturais. Para as primeiras, cita como exemplos, bacias de retenção, detenção e amortecimento, bacias de sedimentação, retenção de detritos e lixo, parques lineares, relocação e demolição de estruturas. Já nas segundas, têm-se os programas de manutenção e inspeção do sistema de drenagem, Manual de Drenagem e de Gestão da Drenagem e institucionalização da drenagem urbana como serviço do estado.

Quanto às medidas estruturais e não estruturais, nem sempre estas são aplicadas durante o planejamento e a gestão da drenagem urbana, implicando diretamente transtornos vivenciados. Portanto, a gestão e o controle da drenagem urbana assumem papel relevante frente ao crescimento das cidades, em relação ao adensamento e impermeabilização do solo nas bacias em espaços urbanos.

A drenagem faz parte do gerenciamento do espaço urbano e segue o Plano Diretor, cuja exigência está regulamentada pelo Estatuto das Cidades e pela Política Nacional de Saneamento Básico (PNSB), Lei Federal no 11.445/2007 (Brasil, 2007), atualizada pela lei 14026 de 15 de julho de 2020 (Brasil, 2020). Enfim, enquanto a cidade cresce, os impactos ambientais a acompanham e estão relacionados a forma do uso e ocupação do espaço urbano, apesar da existência de instrumentos, a exemplo do Plano Diretor de Goiânia, Lei Municipal 171 (Goiânia, 2007).

Neste contexto e no que concerne ao uso de metodologias, como o método CN, voltadas à avaliação das mudanças decorrentes da urbanização acelerada e adensada, Soares et al. (2017) destacam boas correlações alcançadas com base na comparação entre os valores preditos e a realidade observada em diversas bacias hidrográficas.

Assim sendo, na tentativa de compreender a configuração espacial e sistêmica do ambiente, com o presente trabalho objetivou-se avaliar a eficiência hidrológica das áreas com vegetação remanescente, especialmente em parques urbanos, na bacia hidrográfica do córrego Botafogo em Goiânia.

\section{Metodologia}

\subsection{Caracterização da área de estudo}

A área de estudos compreende a bacia do córrego Botafogo localizada na porção central do município de Goiânia, conforme apresentado na Figura 1. Trata-se uma área densamente edificada, cujo processo de urbanização teve início ainda nos primórdios da construção da capital. Em relação ao relevo a área se distribui entre as cotas de 693 m a 892 m, apresentando baixa declividade, especialmente entre as classes de 0 a $7 \%$, sendo que os maiores declives se localizam nas bordas dos principais canais. 
Figura 1 - Localização da bacia do córrego Botafogo (parte a); mapa hipsométrico (parte b); mapa de declividade (parte c); e mapa de comprimento de fluxo (parte d).

a

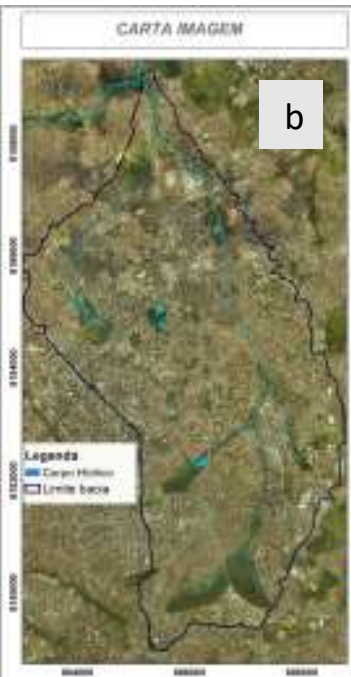

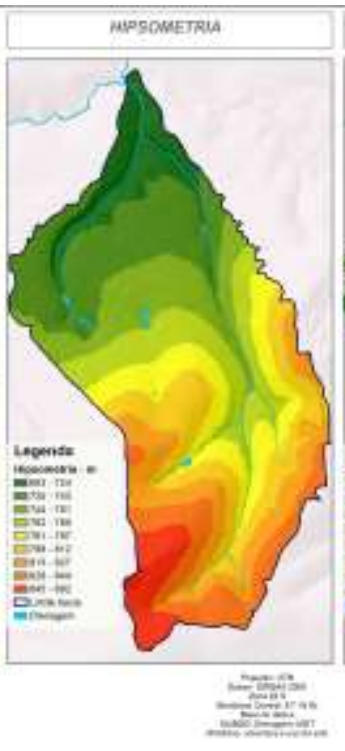

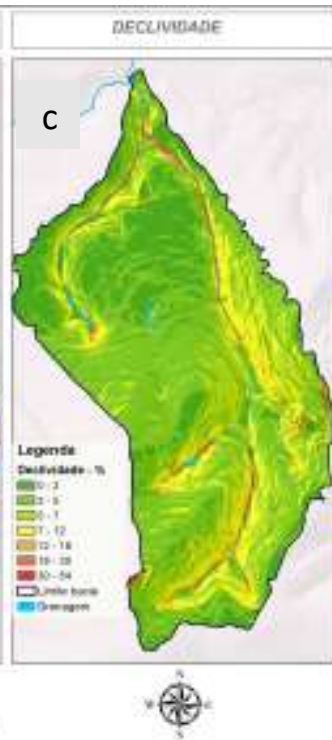

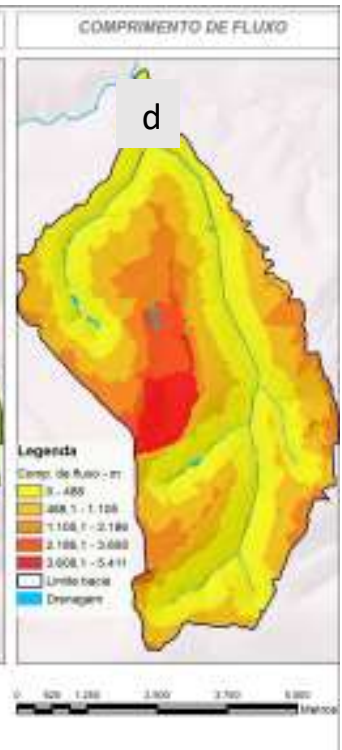

Fonte: Autores.

Os parques urbanos na sub-bacia do córrego Botafogo são 6 (seis): 1) Bosque dos Buritis; 2) Lago das Rosas; 3) Parque Areião, 4) Parque Botafogo; 5) Parque Flamboyant e 6) Jardim Botânico, totalizando área verde de 1,18 km² (Figura 2).

Figura 2 - Localização dos parques existentes na bacia hidrográfica do córrego Botafogo.

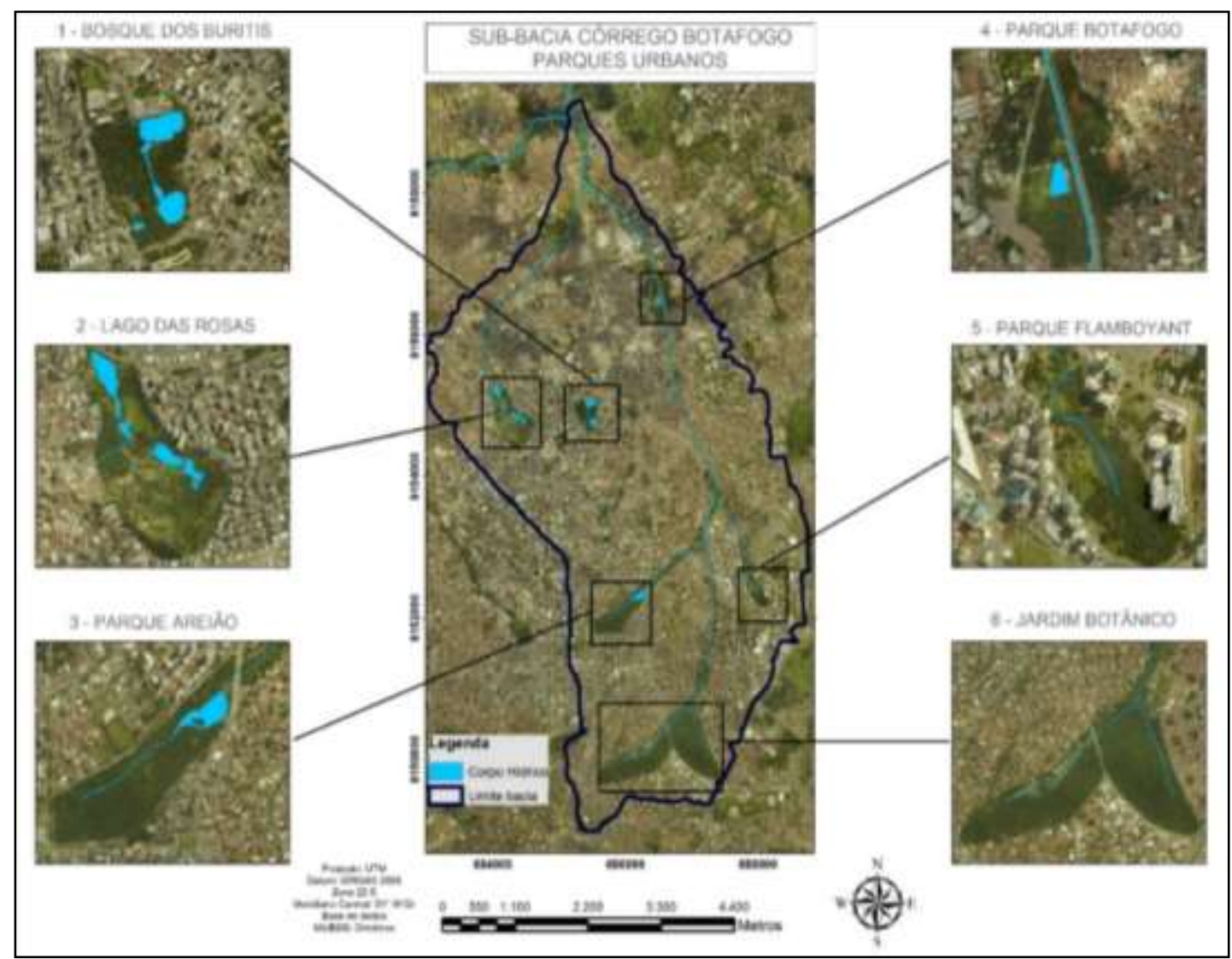

Fonte: SEMDUS/SECTEC (2018). Elaboração: Autores (2019). 


\subsection{Procedimentos Técnico-Operacionais}

\subsubsection{Preparação do banco de dados e mapeamentos}

Todos os dados foram georreferenciados com base na projeção UTM, Datum SIRGAS 2000 e no fuso 22 S. Para classificação da cobertura e uso do solo na sub-bacia, e aplicação do modelo hidrológico empregou-se imagens do satélite Landsat 5 bandas 5, 4 e 3, referentes aos anos de 1988, 1998 e 2008, e Landsat 8 bandas 6, 5 e 4 referente ao ano de 2018, com resolução espacial de 30 m e resolução espectral de sete bandas, obtidas do United States Geological Survey (USGS, 1988, 1998, 2008 e 2018).

Para recortes espaciais detalhados, localização e dimensionamento, foram usadas ortofotos de Goiânia, com 0,60 m de resolução, anos 1992, 2001, 2006, 2011 e 2016, da Secretaria Municipal de Desenvolvimento Urbano Sustentável (SEMDUS) e de arquivos vetoriais do Mapa Urbano Básico Digital de Goiânia (MUBDG), versão 25, da Secretaria Municipal de Ciência, Tecnologia e Inovação (SECTEC).

\subsubsection{Método Racional: variáveis e equacionamento}

As estimativas de volume de escoamento se baseiam na avaliação dos tipos de solo, formação de grupos hidrológicos, condições de cobertura e uso e capacidade de retenção de água e dada pela Equação 1:

$$
\left.Q_{\max }=\frac{C i A}{3,6} \quad \text { (Equação } 1\right)
$$

em que:

Qmax é a vazão máxima estimada do escoamento superficial, em m³/s;

C é o coeficiente de escoamento superficial ou razão entre o volume escoado e o total precipitado, adimensional;

i é a média das intensidades máximas de precipitação, em $\mathrm{mm} / \mathrm{h}$, sendo que para a estimativa de vazão máxima a duração do evento pluviométrico deve ser igual ou maior que o tempo necessário para escoamento em toda a bacia;

A é a área da bacia, em $\mathrm{km}^{2} ;$ 3,6 é o fator de conversão entre unidades.

Os coeficientes de escoamento superficial foram determinados com base na proposta do Serviço de Conservação do Solo (SCS - Soil Conservation Service), aplicada pela Administração Federal de Autoestradas (FHA - Federal Highway Administration, 2013) do Departamento de Transportes dos EUA, baseando-se na precipitação efetiva, a qual resulta da relação entre a precipitação considerada e a capacidade de infiltração de água no solo. Essa relação considera também perda inicial de cerca de $20 \%$ do volume precipitado em decorrência das interceptações e retenções em depressões. Este coeficiente de armazenamento (S), resulta da avaliação de grupos hidrológicos, os quais levam em conta as características dos solos, especialmente textura e profundidade, características do terreno, bem como o tipo de cobertura e uso do solo, resultando em valores de CN (número de escoamento), conforme o Natural Resources Conservation Service (NRCS) - USDA (1997), de acordo com a equação 2. Para o cálculo, considerou-se o solo em condições normais, em que a precipitação acumulada nos últimos 5 dias é maior que $13 \mathrm{~mm}$ e menor que $53 \mathrm{~mm}$.

$$
\mathrm{S}=\frac{25400}{\mathrm{CN}}-254 \quad \text { (Equação 2). }
$$

Já os coeficientes de escoamento resultam da razão entre a precipitação efetiva ou volume convertido em escoamento superficial e a precipitação total a ser considerada, como apresentado na Equação 3:

$$
C=\left[\frac{(p-0,2 s)^{2}}{(p+0,8 s])}\right] * 1 / P \quad \text { (Equação 3). }
$$

em que: 
$\mathrm{C}=$ coeficiente de escoamento superficial ou razão entre o volume escoado e o total precipitado, adimensional.

Para aplicação das Equações 2 e 3, baseia-se nos números de escoamento superficial $(\mathrm{CN})$ para cada o tipo de condição do terreno na bacia, conforme apresentado no Tabela 1.

Tabela 1 - Classes de uso e ocupação do solo e respectivos números de escoamento superficial (CN).

\begin{tabular}{ll}
\hline Condição do Terreno & CN \\
\hline Área Edificada & 98 \\
Superfície Pavimentada & 97 \\
Solo Exposto Compactado & 76 \\
Solo Exposto não Compactado & 68 \\
Gramínea Compactada & 66 \\
Gramínea não compactada & 61 \\
Árvores Isoladas & 62 \\
Mata de Galeria/Vegetação Densa & 29 \\
\hline
\end{tabular}

Fonte: Tucci e Marques (2001).

As médias das intensidades máximas de precipitação estimadas, que relaciona a intensidade-duração-frequência, entendido pela sigla IDF, dos eventos meteorológicos, utilizando o histórico de chuvas disponibilizados pelo INMET para o período correspondente a esta pesquisa, conforme sistematizado por Oliveira et al. (2005) para a região de Goiânia. por meio da seguinte Equação 4:

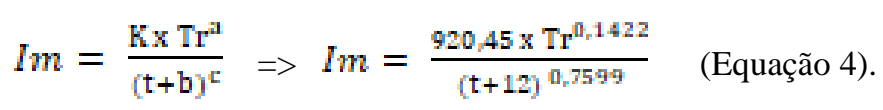

em que:

Im é a média das intensidades máximas de precipitação, em mm/h;

K, a, b e c são os parâmetros próprios da estação climatológica;

$\mathrm{T}$ é o tempo de retorno, em anos para um evento extremo;

t é o tempo de concentração do escoamento superficial, que deve ser menor ou igual ao tempo de duração da precipitação na área da bacia, em minutos.

Considerou-se tempo de retorno de 50 anos, compatível com áreas comerciais e vias arteriais de tráfego. Já os tempos de duração das precipitações resultaram do tempo de concentração do escoamento superficial de toda a bacia, estimados no período de estudo de 1988 até 2018, determinados pelo Método Cinemático, por meio da Equação 5:

$$
T c=1 / 60 x \Sigma \frac{L i}{V i} \quad \text { (Equação 5). }
$$

em que:

Tc é o tempo de concentração do escoamento superficial, em min;

$1 / 60$ é o fator de transformação de segundos para minutos;

Li é o comprimento de fluxo no segmento considerado, em m;

Vi é a velocidade do escoamento superficial, em $\mathrm{m} / \mathrm{s}$.

A velocidade de escoamento superficial foi estimada com base na avaliação dos coeficientes de escoamento e da declividade, conforme Equação 6: 


$$
V_{i}=C x S_{i}^{0,5} \quad \text { (Equação 6). }
$$

em que:

Vi é a velocidade de escoamento superficial, em $\mathrm{m} / \mathrm{s}$;

C é o coeficiente de escoamento superficial, adimensional;

Si é a declividade, em \%, elevada ao expoente $0,5, \mathrm{em} \mathrm{m} / \mathrm{m}$;

Aplicou-se coeficiente de retardamento em função da área da mesma, resultando no que se conhece como Método Racional Modificado, cuja fórmula é apresentada pela Equação 7:

$$
\theta=0,278-0,000345 \quad \text { (Equação 7). }
$$

em que:

$\theta$ é o coeficiente de retardamento em função da área da bacia;

0,278 e 0,00034 são constantes;

$\mathrm{S}$ é a área da bacia em $\mathrm{km}^{2}$.

Ressalta-se que a variável área da bacia é de forma cumulativa, isto é, transferência do volume de células a montante para aquela a jusante, que resultará no acúmulo de escoamento superficial em função da área de contribuição específica (Nunes \& Borba, 2018).

\subsubsection{Precipitação efetiva}

Segundo Oliveira et al. (2005), para a utilização prática e adequada dos dados de chuva na elaboração de projetos de drenagem, barragens, obras de proteção contra cheias e estudos hídricos, faz-se necessário conhecer a relação intensidadeduração-frequência das chuvas intensas na bacia.

Thompson (2006) explica que as curvas Intensidade-Duração-Frequencia (IDF) podem ser determinadas pela análise de tempestades para um determinado local ou pelo uso de atlas meteorológicos padrão. Neste sentido, conforme o método racional e equacionamento, as intensidades médias máximas de precipitação (IMMP), sendo sistematizado por Oliveira et al. (2005) para a região de Goiânia.

Os tempos de duração das precipitações resultaram do tempo de concentração do escoamento superficial da bacia. Estas informações subsidiaram a estimativa do coeficiente $\mathrm{K}$, da velocidade de escoamento superficial e tempo de concentração, no período de estudo, de 1988 até 2018. Após, determinou-se a precipitação considerada ( $\mathrm{Pc}$ ), que é o produto da IMMP multiplicado pelo tempo de concentração em horas.

\subsubsection{Coeficiente de infiltração e escoamento superficial}

O coeficiente de infiltração (S) ou coeficiente de armazenamento, expressa a capacidade de retenção da precipitação efetiva no solo, ou seja, de acordo com Liang, Cao \& Wu (2018) a retenção de água, a permeabilidade instaurada e as características de infiltração dependem da análise das características solo+água (cobertura e uso + precipitação). Já Carvalho (2014) define que o coeficiente de escoamento superficial (CES) é um parâmetro adimensional, representa a relação entre o volume que escoa sobre a superfície do terreno e o volume precipitado. A partir de dados de CN (número de escoamento) apresentados por Nunes \& Borba (2018) foi possível estabelecer o coeficiente de escoamento superficial (CES).

\subsubsection{Aplicação esquematizada do modelo hidrológico}

De forma a esquematizar a sequência metodológica utilizada na aplicação do modelo hidrológico, é apresentada no fluxograma básico, por meio da Figura 3. 
Research, Society and Development, v. 10, n. 15, e15101519980, 2021

(CC BY 4.0) | ISSN 2525-3409 | DOI: http://dx.doi.org/10.33448/rsd-v10i15.19980

Figura 3 - Fluxograma metodológico para aplicação do modelo hidrológico.

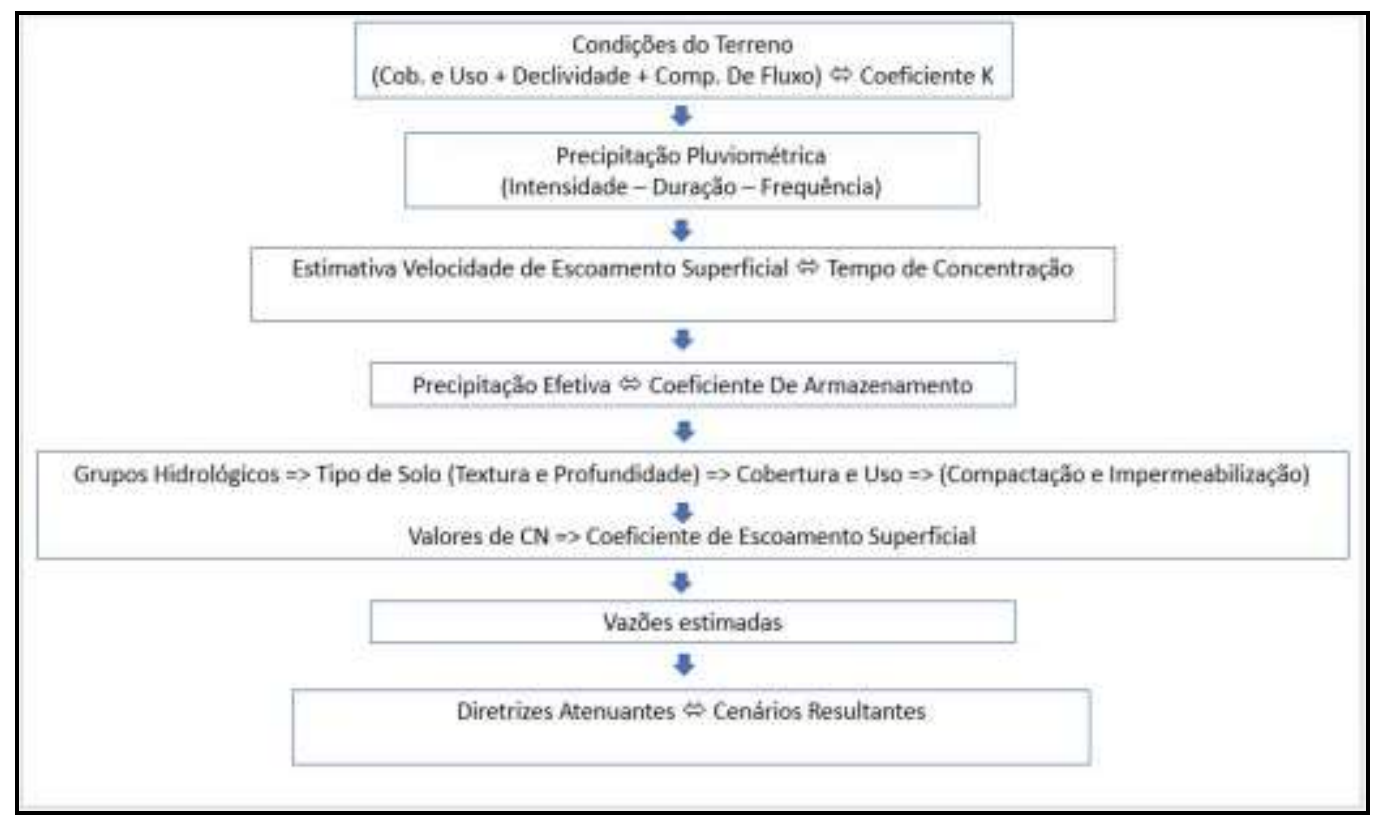

Fonte: Autores (2019).

Ressalta-se que os cálculos foram realizados por meio de modelagem no software ArcGis 10.3, a partir de álgebra matricial.

\section{Resultados e Discussão}

Ao longo das Figuras 4 e 5 é apresentado a distribuição espacial e percentual, respectivamente, de cada classe de cobertura e uso do solo na bacia hidrográfica do córrego Botafogo. Por meio da série temporal de mapas e pelo gráfico é possível constatar um discreto aumento das áreas edificadas em detrimento das áreas com vegetação remanescentes. Este pequeno aumento se deve ao fato de que a partir de 1988 a bacia já se encontrava densamente urbanizada, remanescendo vegetação apenas nos parques. 
Figura 4 - Classes de uso e ocupação do solo na bacia do córrego Botafogo nos anos de 1988, 1998, 2008 e 2018.
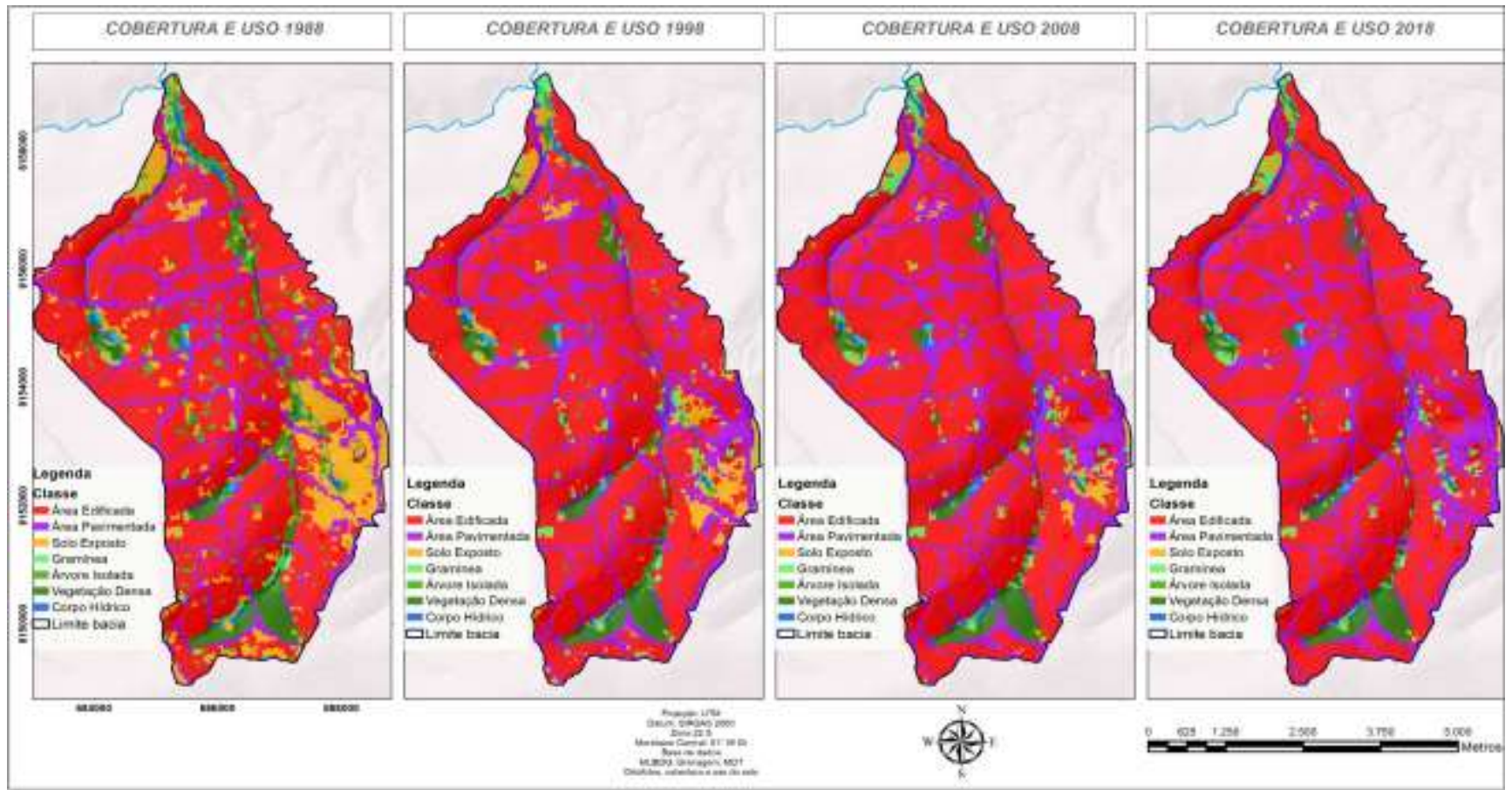

Fonte: Autores.

Figura 5 - Distribuição de área - \% - na bacia córrego Botafogo nos anos de 1988, 1998, 2008 e 2018.

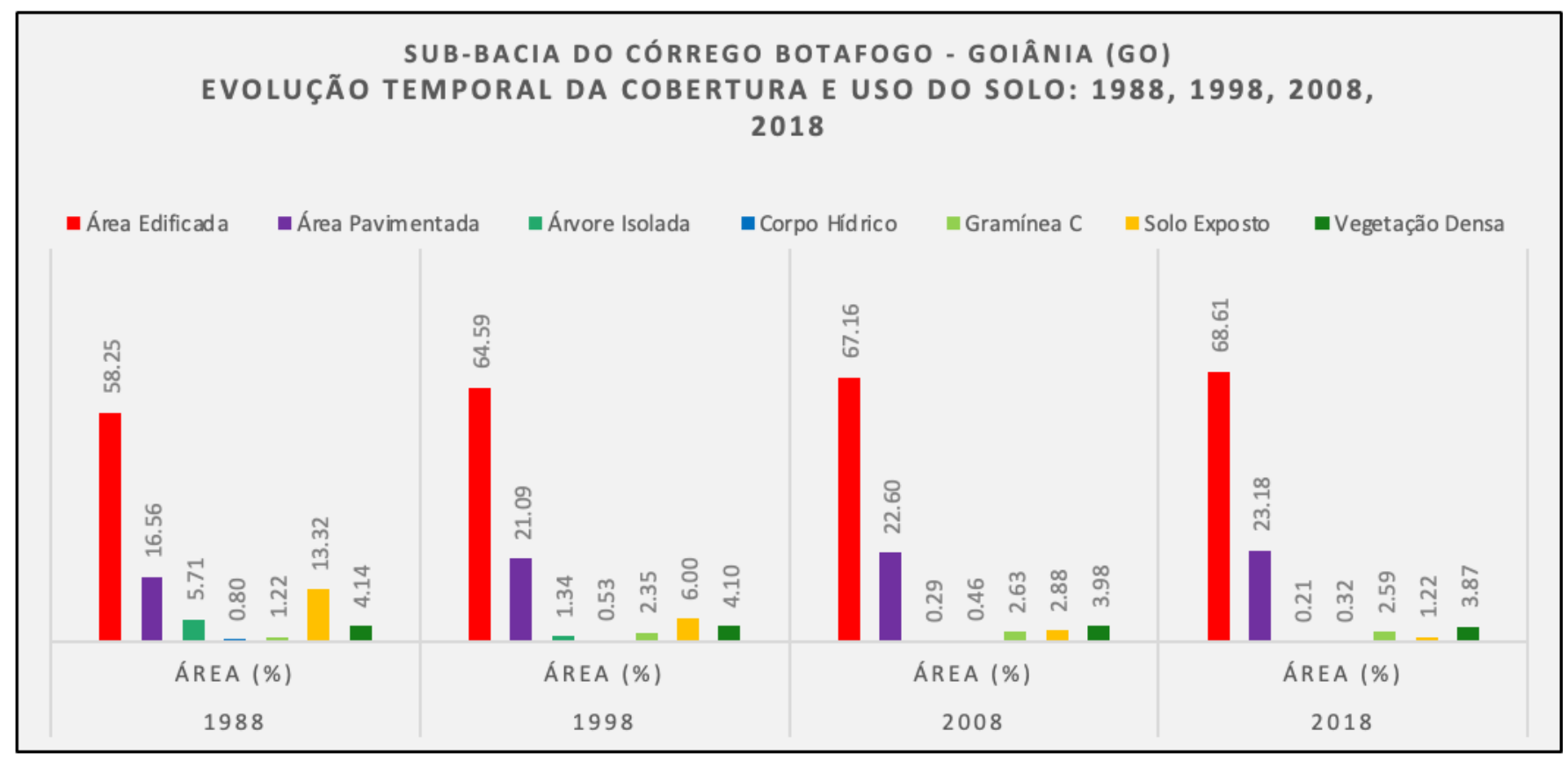

Fonte: Autores.

Na Figura 6, percebe-se que assim como ocorreu com o coeficiente K, a maior transformação para os valores estimados de velocidade de escoamento superficial se deu de 1988 para 1998, influenciado pelo grau de antropização ocorrida na sub-bacia, ou seja, as alterações temporais de velocidade do escoamento superficial são influenciadas pelas transformações de cobertura e uso do solo. O coeficiente K é uma variável adimensional que corresponde ao grau de antropização ocorrida em determinada área. 
Observa-se que as mudanças espaciais para estimativas de velocidade de escoamento superficial são mais influenciadas pela declividade do terreno na área em questão. Portanto que a estimativa de velocidade nas porções mais planas, localizada na porção central baixa da sub-bacia, próximo ao exutório final, a velocidade tende a se manter no máximo em 1,1 m/s, no geral. Quando se aproxima das bordas dos canais fluviais, onde a declividade é maior, a estimativa de velocidade também aumenta, chegando a $4,3 \mathrm{~m} / \mathrm{s}$, ou seja, devido a inclinação mais acentuada nessa porção, o volume de água dobra, quadriplicando a estimativa de velocidade de escoamento.

De forma geral, tem-se que as estimativas de aumento de velocidade máxima de escoamento superficial foi de 4,3 m/s em 1988 para 4,38 m/s em 2018, permanecendo praticamente estável. Já da velocidade média foi de 1,048 para 1,115 m/s, isso significa que houve aumento proporcional na média ponderada de toda sub-bacia ao longo dos anos, influenciada diretamente pela impermeabilização do solo, ou seja, alterações de cobertura e uso do solo, especialmente com construções habitacionais e redução da área verde, fazendo com que o acúmulo de água chegue com maior velocidade e em menor tempo de concentração no canal do córrego Botafogo, conforme comprovado posteriormente.

Figura 6 - Estimativas de velocidade e escoamento superficial para os anos de 1988, 1998, 2008 e 2018 na sub-bacia do córrego Botafogo, Goiânia, GO.

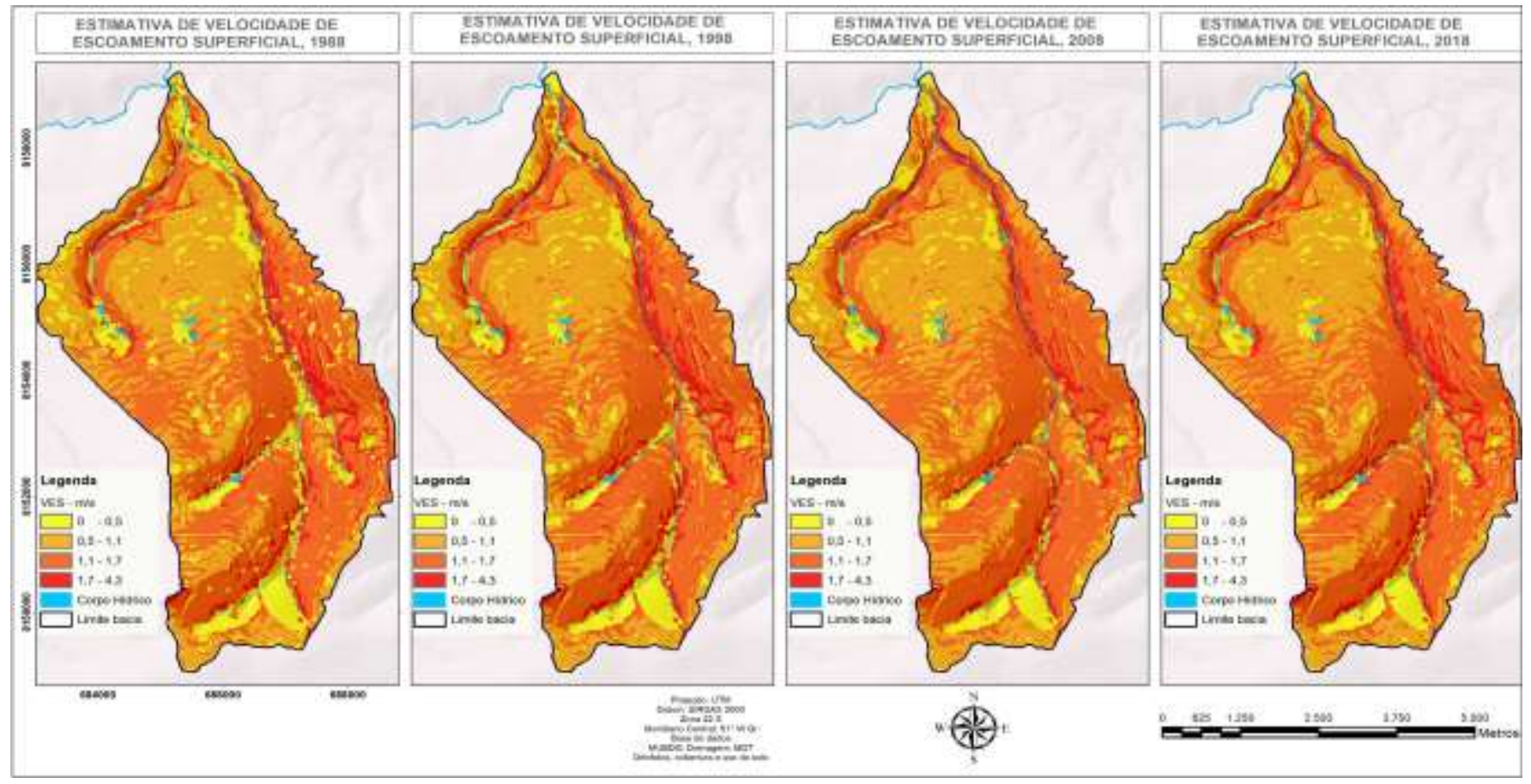

Fonte: SEMDUS/SECTEC (2018). Elaboração cartográfica pelos autores (2019).

Quanto a precipitação efetiva verificou-se na Tabela 2 que toda sub-bacia contribui para o efeito acumulativo do volume de água no canal principal, gerando cenários de transbordamento, pois o tc diminuiu ao longo do tempo, ao passo que a IMMP aumentou. Neste aspecto, Thompson (2006) explica que a intensidade das chuvas é uma função da localização geográfica e intervalo de retorno, sendo que quanto maior o intervalo de retorno maior a intensidade da precipitação para uma dada tempestade duração e menor o tempo de concentração. 
Tabela 2 - Precipitação considerada na sub-bacia do córrego Botafogo para os anos de 1988, 1998, 2008 e 2018.

\begin{tabular}{rcrcc}
\hline \multicolumn{1}{l|}{ Ano } & IMMP $(\mathbf{m m})$ & TC $(\mathbf{m i n})$ & TC $(\mathbf{h})$ & \multicolumn{1}{c}{ Pc $(\mathbf{m m})$} \\
\hline 1988 & 48,98 & 86,72 & 1,44 & 70,79 \\
1998 & 50,84 & 82,00 & 1,36 & 69,48 \\
2008 & 51,15 & 81,25 & 1,35 & 69,27 \\
2018 & 51,30 & 80,88 & 1,34 & 69,15 \\
\hline
\end{tabular}

Fonte: Autores (2019).

Além disso, quanto maior o comprimento da tempestade, menor a média da tempestade (intensidade de precipitação). Isso reflete diretamente na diminuição da precipitação considerada ao longo do tempo, que é transformada em precipitação efetiva (Figura 7).

Figura 7 - Precipitação efetiva para os anos de 1988, 1998, 2008 e 2018 na sub-bacia do córrego Botafogo, Goiânia, GO.

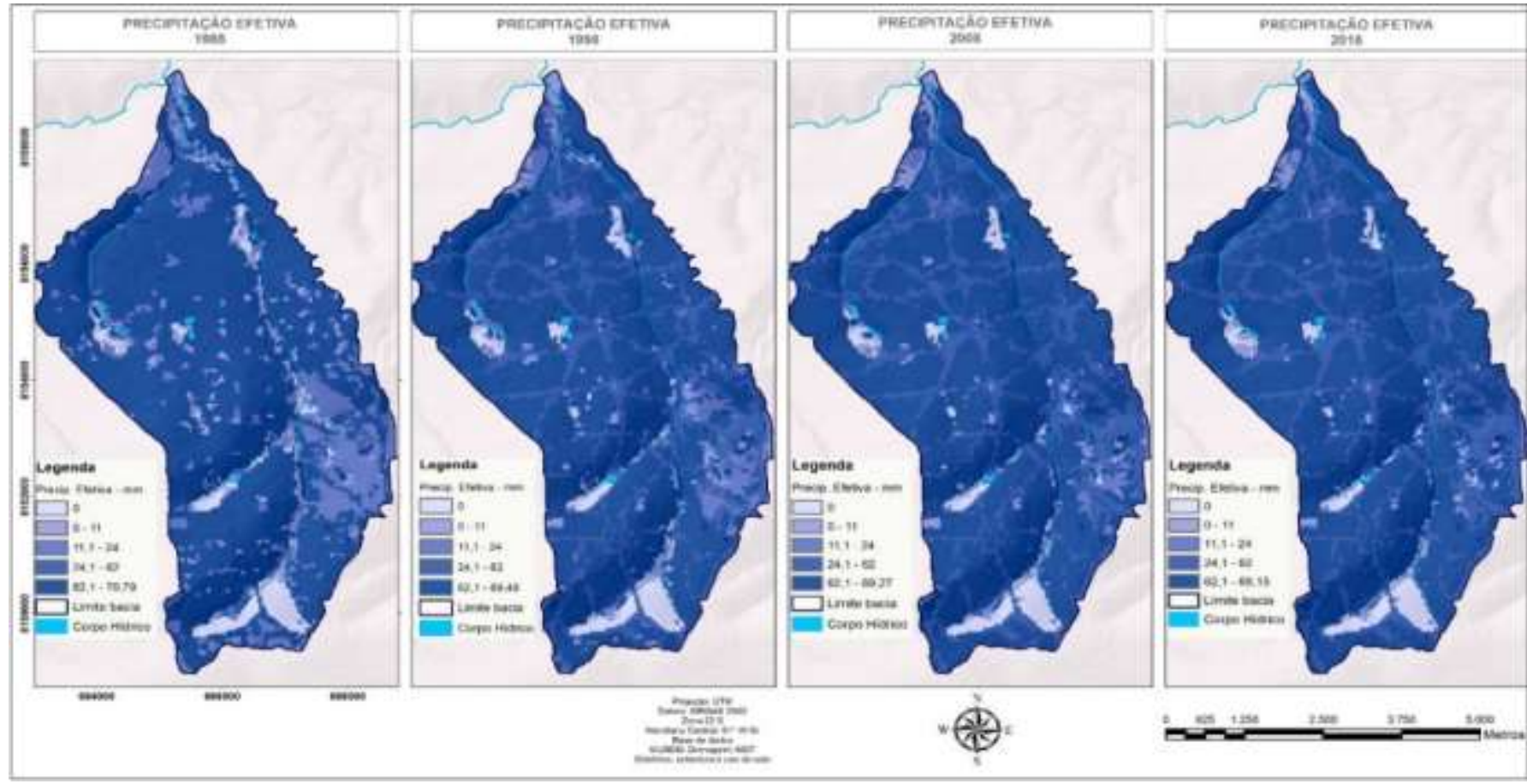

Fonte: SEMDUS/SECTEC (2018). Elaboração cartográfica pelos autores (2019).

A precipitação efetiva corresponde ao volume (coluna d'água) que é transformado em escoamento superficial. Esta precipitação é pontual, pois está relacionada a cobertura e uso do solo, mas factível de dimensionamento, visibilidade e análise distribuída na sub-bacia. Em 1988, é perceptível que há áreas à direita do córrego Botafogo possuíam precipitações efetivas entre $0-11 \mathrm{~mm}$, as quais gradativamente vão sendo alteradas pelo processo de construções, ficando evidente em 2018 elevações nas precipitação efetiva, especialmente na região sudeste de Goiânia.

Assim, constata-se que nas áreas de vegetação densa (parques urbanos) e vegetações remanescentes são os ambientes em que não há precipitação efetiva, ou seja, não existe contribuição para o escoamento superficial, pois espera-se possam contribuir com até $100 \%$ para a infiltração.

Quanto ao coeficiente de escoamento superficial, foi possível verificar a determinação do coeficiente $\mathrm{S}$ na sub-bacia do córrego Botafogo para os anos de 1988, 1998, 2008 e 2018 (Figura 8). Para que a infiltração ocorra é necessário que haja 
precipitação efetiva, o chamado input. Quando a precipitação encontra o solo vai ocorrer a percolação ou o escoamento superficial, dependendo da cobertura naquele local específico.

Então, percebe-se, que o coeficiente $\mathrm{S}$ é muito semelhante, visualmente, com o mapeamento de cobertura e uso do solo. Nota-se que a cobertura do solo na bacia hidrográfica é predominantemente urbanizada, destacando-se os bairros Alto da Glória, Jardim Goiás e Universitário, Pedro Ludovico e Setor Sul. Estes bairros foram estimulados pela atração do Shopping Flamboyant e posteriormente pelo deslocamento do Paço Municipal e surgimento de condomínios horizontais na saída sul e sudeste da capital.

Onde há vegetação, especialmente nas áreas de preservação permanente, ou nos parques urbanos, a capacidade de infiltração é maior, ou seja, retém até $621,86 \mathrm{~mm}$ de água precipitada. Ressalta-se que a capacidade de armazenamento permanece constante ao longo das décadas estudadas. O que altera é apenas a distribuição espacial, com diminuição de remanescentes de áreas verdes, que possuem maior capacidade de percolação, e aumenta as áreas edificadas e pavimentadas, nestas com coeficiente $\mathrm{S}$ de $0-4,8 \mathrm{~mm}$ e de 4,81-7,3 $\mathrm{mm}$, respectivamente.

À margem direita do canal principal, influenciada pelo grau de urbanização nos setores que formam esta faixa na área estudada, associado ao fato da vertente da sub-bacia nesta margem ser delimitada pela BR-153, percebe-se que substancialmente a estimativa de velocidade de escoamento superficial é mais alta, ficando entre 1,7 e 4,3 m/s. A margem esquerda do canal principal, a maior contribuição é dos setores, também fortemente adensados, apresentando estimativa de velocidade de escoamento de 1,1 a $1,7 \mathrm{~m} / \mathrm{s}$.

Figura 8 - Coeficiente de infiltração (S) para os anos de 1988, 1998, 2008 e 2018 na sub-bacia do córrego Botafogo, Goiânia, GO.

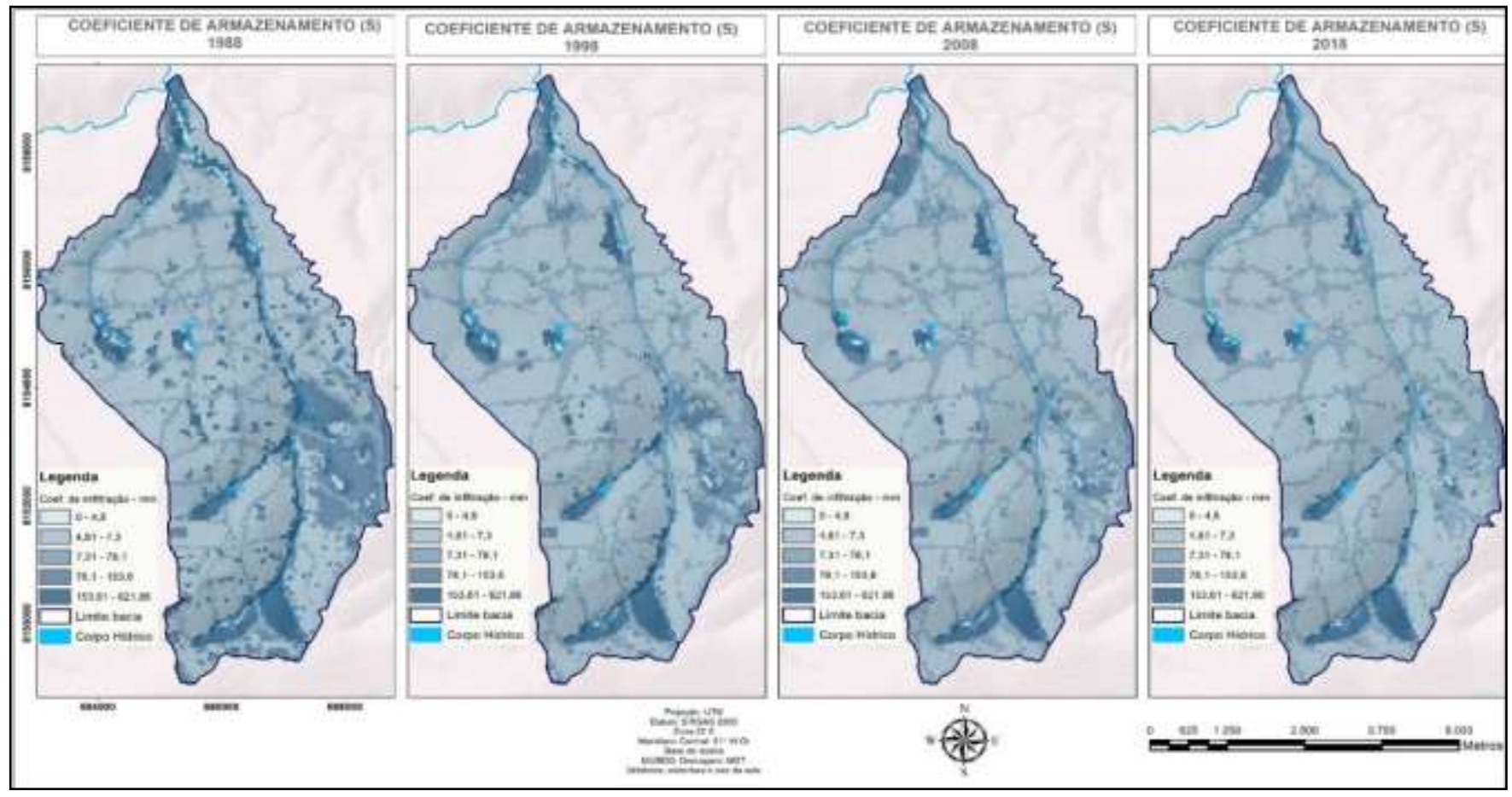

Fonte: SEMDUS/SECTEC (2018). Elaboração cartográfica pelos autores (2019).

Quanto ao escoamento superficial destaca-se na Tabela 2, devido os valores de precipitação efetiva e coeficientes de escoamento superficial que dependem das condições de cobertura e uso, da precipitação considerada em face dos coeficientes de armazenamento, de forma que quanto mais duradoura e intensa for a chuva, maior será a precipitação efetiva, bem como os coeficientes de escoamento superficial (Nunes \& Borba, 2018). 
Analisando a Figura 9, percebe-se a relação estabelecida entre a precipitação efetiva com o escoamento superficial. Observa-se que nos ambientes em que CES é 0, nas áreas de vegetação densa, não houve precipitação efetiva, bem como não acontece escoamento superficial, pois nestas áreas há infiltração no solo. Consequentemente, nos espelhos d'água (lagos e canais fluviais) é que ocorre o valor máximo de CES, ficando com 1, bem como nas mesmas áreas em a precipitação efetiva máxima ocorre, fatores estes que influenciam nas estimativas de vazão, conforme apresentado posteriormente.

Figura 9 - Coeficiente de escoamento superficial (CES) para os anos de 1988, 1998, 2008 e 2018 na sub-bacia do córrego Botafogo, Goiânia, GO.

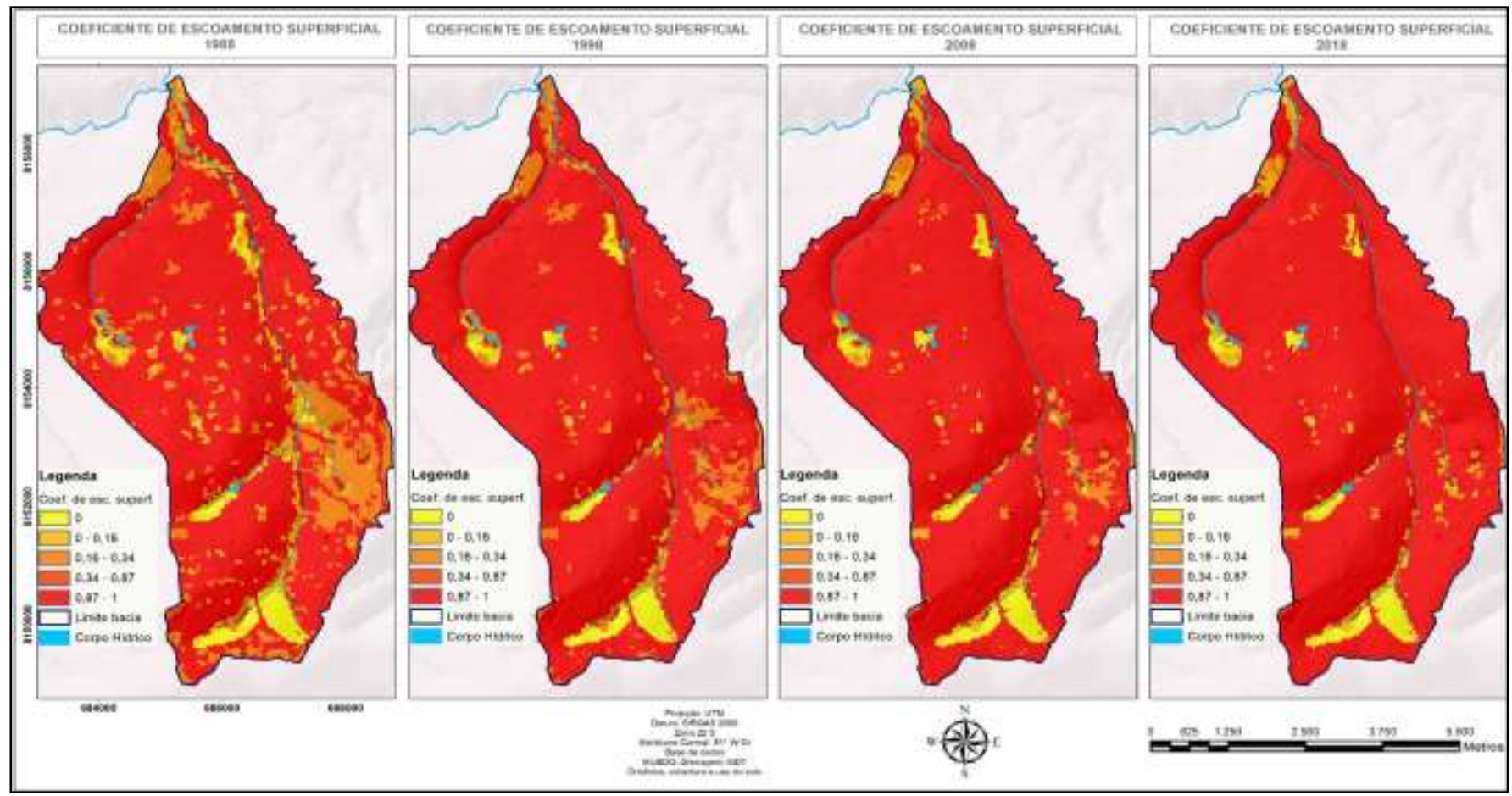

Fonte: SEMDUS/SECTEC (2018). Elaboração cartográfica pelos autores (2019).

Basicamente a maior alteração se dá, como esperado, da década de 1988 para 1998, com a diminuição de áreas verdes que cederam espaço às áreas pavimentas e edificadas. De 1998 para 2008 as alterações no CES ocorrem em menor porcentagem, sendo visível essa diminuição de áreas verdes e solo exposto para aumento de áreas pavimentas e edificadas, principalmente localizadas no meio da sub-bacia, na cabeceira e na porção direita, onde se insere o Jardim Goiás, que conforme já comentado, passou por valorização dos terrenos vazios e forte adensamento nos últimos anos.

Em 2018 a sub-bacia se apresenta praticamente sem espaços vazios, fortemente impermeabilizada. Nota-se os extremos predominantes para valores de CES, com 0 nos remanescentes de vegetação, pequenas faixas de coeficiente de escoamento superficial, variando de 0,16-0,34, nas porções de gramíneas compactadas e na maior parte da sub-bacia, quase que sua totalidade, com CES entre 0,87 e 1, consequência do forte grau de impermeabilização.

Em outro estudo, Moruzzi et al (2017) avaliaram a capacidade de retenção de material suspenso em áreas gramadas, concluindo haver remoções da ordem de $50 \%$ para a posição de $50 \mathrm{~m}$ do canal gramado e de $70 \%$ para a posição de 80 m. Os resultados mostraram que a remoção de material particulado é fortemente dependente da extensão do canal e que os aspectos dinâmicos decorrentes da passagem da onda de cheia influenciam no processo. A simples presente de grama, facilita a infiltração da água e reduz processos erosivos e assoreamento dos canais de drenagem.

Rezende et al. (2015) ao verificar as taxas de impermeabilização e tempo de concentração das sub-bacias presentes na área urbana de Barra do Garças - MT, Pontal do Araguaia - MT e Aragarças - GO, perceberam que áreas já urbanizadas, o 
grau de impermeabilização e tempo de concentração das sub-bacias apresentaram níveis considerados "médios e altos", o que é preocupante, devido a relação dessas variáreis ao crescimento das vazões e volume escoado, e, consequentemente, aumento da frequência de inundações.

Para Bezerra et al. (2020), ao estudarem uma bacia hidrográfica em Brasília, propuseram medidas de infraestrutura verde, que significam a maximização da infiltração e um percentual menor de escoamento, para ser resolvido por técnicas tradicionais, significando maior equilíbrio ecossistêmico e redução de impactos ambientais.

Como soluções mais viáveis para o uso na drenagem urbana, Lopes et al. (2020) identificaram medidas que utilizam pequenas áreas para a retenção das águas da chuva, em lotes individuais ou em áreas públicas, tais como, reservatórios de lote e pavimento permeável. Canabrava Neto (2021) lista, dentre as alternativas, o uso do telhado verde, o qual contribui para a gestão da drenagem urbana, auxiliando na captação das águas pluviais, podendo melhorar a qualidade do ar e da água, diminuindo a sobrecarga do escoamento

Deste modo, estímulos com medidas estruturais e não-estruturais, como os exemplos acima, associado à legislação sobre uso e ocupação do solo, incentivo ao aumento de áreas permeáveis em lotes com redução de impostos ou mesmo premiações as melhores práticas, podem promover a infiltração e/ou retardamento das águas pluviais.

\section{Conclusão}

Verificou-se que a existência de parques (áreas verdes) e vegetação remanescente amenizam ou retardam o surgimento de enxurradas pontuais e/ou alagamentos, que consequentemente se acumulam em volume proporcional ao escoamento superficial, devido a porcentagem elevada de área impermeabilizada, gerando o efeito acumulativo no canal principal.

Sugere-se que as estruturas de drenagem nos empreendimentos, especialmente em shopping, hipermercados, estádios sejam considerados relevantes, assim como adoção de pisos com material permeável e telhados verdes, de forma a diminuir a contribuição destas áreas com o escoamento superficial nas bacias que se localizam.

É importante destacar, que o envolvimento e parcerias futuras, entre a academia e órgãos gestores, poderá contribuir para definições de melhorias nas políticas de planejamento urbano, principalmente em relação aos planos de controle de águas pluviais e de drenagem urbana.

\section{Agradecimentos}

A CAPES pela bolsa de pesquisa.

\section{Referências}

Araújo, G. H. S., Almeida, J. R., \& Guerra, A. J. T. (2008). Gestão Ambiental de Áreas Degradadas. Bertrand Brasil.

Bezerra, M do C. de L, Óliveira, A. da N., Costa, M. E. L., \& Koide, S. (2020). Simulação de técnicas de infraestrutura verde de drenagem urbana para captação do escoamento superficial. Revista Tecnologia e Sociedade, 16 (40), 1

Brasil. (2007). Lei 11.445, de 05 de janeiro de 2007. Política Nacional de Saneamento Básico. Estabelece diretrizes nacionais para o saneamento básico. Brasília: Diário Oficial da União.

Brasil. (2020). Lei n 14.026, de 15 de julho de 2020. Atualiza o marco legal do saneamento básico. Diário Oficial da União.

Canabrava Neto, E. G., Almeida, A. K., Leite, I. R., Guarienti, J. A., \& De Almeida, I. K (2021). Telhado verde: alternativa sustentável para a drenagem do escoamento superficial. MIX Sustentável, 7 (2), .125-136

Carvalho, D. F. (2014). Planejamento e manejo da água na agricultura irrigada. Viçosa, Ed. UFV.

FHA - Federal Highway Administration. (2013). Urban Drainage Design annual, Hydraulic Engineering. (3a ed.), National Highway Institute, USDT.

Goiânia. (2007). Plano Diretor. Lei Complementar no 171 de 29 de maio de 2007. Secretaria Municipal de Planejamento e Urbanismo - SEPLAM. 
Research, Society and Development, v. 10, n. 15, e15101519980, 2021

(CC BY 4.0) | ISSN 2525-3409 | DOI: http://dx.doi.org/10.33448/rsd-v10i15.19980

Hammond, M. J., Chen, A. S., Djordjević, S., Butler, D., \& Mark, O. (2013). Urban flood impact assessment: a state-of-the-art review. Urban Water Journal, $12,14-29$.

Kneib, E. C. (2016). Centralidades urbanas e sistemas de transporte público em Goiânia, Goiás. Revista Brasileira de Gestão Urbana, 8(3), 306-317.

Liang, C., Cao, C., \& Wu, S. (2018). Hydraulic-mechanical properties of loess and its behavior when subjected to infiltration-induced wetting. Bulletin of Engineering Geology and the Environment, 77 (1), 385-397.

Lopes, W. G. R., Lima Júnior, J. M., \& Matos, K. C. (2020). Impactos do crescimento de áreas impermeáveis e o uso de medidas alternativas para a drenagem urbana. Research, Society and Development, 9 (9), e213997102

Martins, J. R. S. (2012). Gestão da drenagem urbana: só tecnologia será suficiente? Escola Politécnica. Artigo Científico. 1-11.

Moruzzi, R. B., Felipe, M., Barbassa, A. P., \& Sírio, D. de L. N. (2017). Avaliação do desempenho de canal gramado na remoção de material suspenso em escoamento superficial pluvial. Engenharia Sanitária e Ambiental, 22 (3), 501-511

Nunes, E. D., \& Borba, L. L. (2018). Avaliação dos efeitos do adensamento urbano na dinâmica hidrológica de bacias hidrográficas - Aparecida de Goiânia GO. Boletim Goiano de Geografia, 38 (2), 205-226.

Oliveira, L. F. C., Cortês, F. C., Wehr, T. R., Borges, L. B., Sarmento, P. H. L., \& Griebeler, N. P. (2005). Intensidade-duração-frequência de chuvas intensas para localidades no estado de Goiás e Distrito Federal. Pesquisa Agropecuária Tropical, Goiânia, 35 (1), $13-18$.

Rezende, G. B. M, \& Araujo, S. M. S. (2015) Análise da taxa de impermeabilização e tempo de concentração nas sub-bacias da área urbana de Barra do Garças - MT, Pontal do Araguaia- MT e Aragarças - GO. Revista verde de agroecologia e desenvolvimento sustentável, 10 (1), 27

Santiago, D. R. et al. (2020). Convivência da cidade com seus rios: estudo da paisagem ribeirinha em Teresina, Piauí, Brasil. Research, Society and Development 9 (11), e1209119582

Secretaria Municipal de Ciência e Tecnologia. Prefeitura Municipal de Goiânia. (2018). arquivos vetoriais do Mapa Urbano Básico Digital de Goiânia (MUBDG), versão 25. Goiânia: SECTEC.

Secretaria Municipal de Desenvolvimento Urbano Sustentável. Prefeitura Municipal de Goiânia. (2018). Ortofotos do município de Goiânia, Goiás. 1992, 2001, 2006, 2011 e 2016. Goiânia: SEMDUS.

Soares, M. R. G. J., Fiori, C. O., Silveira, C. T., \& Kaviski, E. (2017). Eficiência do método Curve Number de retenção de águas pluviais. Mercator, Fortaleza, $16(1) 1-16$

Software Arcgis. Versão 10.3. ArcMap. ESRI - Official Distributor, portadora de direitos sobre a plataforma. Laboratório de informática da Pontifícia Universidade Católica de Goiás.

Thompson, D. B. (2006). The Rational Method. Texas Tech University: Civil Engineering Department

Tucci, C. E. M. (2008). Águas Urbanas. Revista Estudos Avançados, 22 (63), 97-112.

Tucci, C. E. M., \& Marques, D. M. L. da M. (2001). Avaliação e controle da drenagem urbana. UFRGS

USGS - United States Geological Survey - Serviço Geológico dos Estados Unidos. Imagens de satélite: Landsat 5 e Landsat 8 . Anos: 1988, 1998, 2008 e 2018. 